\title{
Research on the QTranslate Secondary Platform for Business Exchange in Real-time Business English System
}

\author{
Xi-Wen ZHANG
}

Foreign Languages' College, Beihua University, Jilin 132013, China.

\section{KEYWORD: QTranslate; Business English; Remote online communication}

ABSTRACT: with the development of the internationalization process rapidly, the barriers to international business exchanges have become increasingly prominent. The QTranslate secondary platform for business exchange in real-time business English system has been applied in remote online communication. The tests results show that the application of QTranslate secondary platform has great help to all exchanges.

\section{GENERAL INSTRUCTIONS}

Business English is a highly professional practical English technology, its main content is English knowledge and practical skills and business-related. Different from ordinary translation, business English translation only for business-related translation in English, knowledge is also involved in business and trade aspects of business knowledge level translators have certain requirements, also includes some unique features. During business English translation activities, we should fully understand the nature of vocabulary and language features of business English, translation techniques and translation strategies focusing on business English translation of a variety of cross-cultural context can better grasp, in order to translate the most standard business English statement, and fully guarantee the effectiveness of business English translation. The following authors actual work experience to talk briefly about how best to conduct business in English translation in a cross-cultural context of the premise.

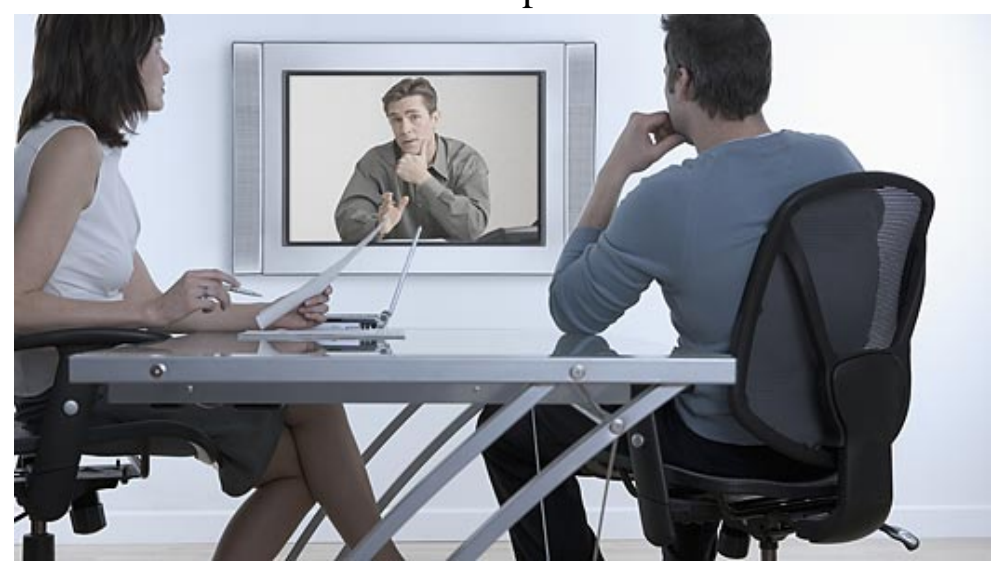

Figure 1.Remote business communication schematic

In the context of cross-cultural context, whether it is cultural differences or ideas will largely affect the business English translation, and may even lead to business English translation lied, impede the normal development of the actual commercial activities. So, we business English translation professionals in order to ensure the accuracy and reliability of the translation results, we must have some research to a variety of business knowledge and customs of Western culture, in business English translation in objective faithfully as possible to restore Business English originally meant to remove obstacles to cross-cultural activities to ensure its smooth and orderly operation of it. During business English translation, it is necessary to follow the basic translation principles, while also fully take into account cultural differences, which the professionalism of our translators put forward higher requirements. 


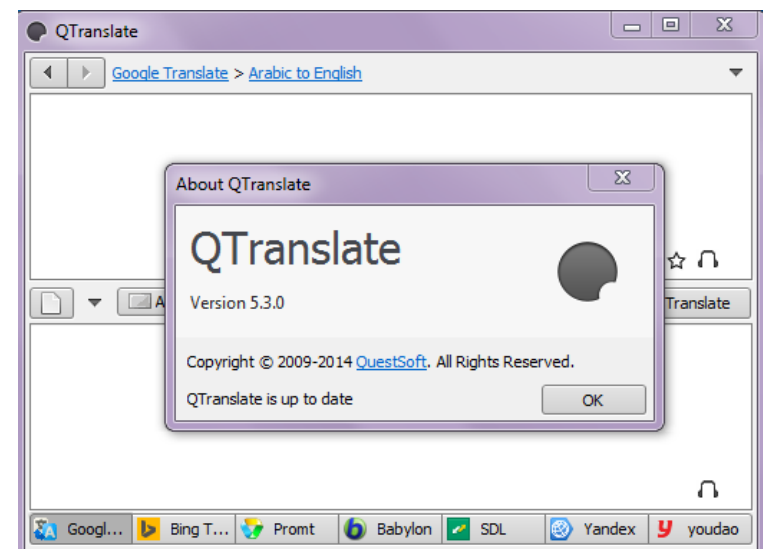

Figure 2. The QTranslate Secondary Development Software Interface Figure

Some of our professional business English translators at foreign trademark or content in English translation, translation methods commonly used to combine literal translation and, for some Western meaning quite different materials on the introduction of paraphrase translation methods.

\section{BUSINESS ENGLISH OVERVIEW}

As an important branch of general English teaching business English is the projection of ordinary English real social function, corresponding to the commercial activities of English applications, business activities are subject to the requirements came into being. Business English from General English but higher than ordinary English, is to extend and improve general English in business activities, but can not exist in isolation from the general English, business English translation to be so ordinary English based. Business English content both business knowledge and knowledge of English, compared to general English teaching business English both common personality, so apart from ordinary English Language learning but also for business knowledge to strengthen and consolidate in order to ensure translators have some basic business English and can be used in the actual translation.

The main features of business English language as follows: term straightforward, concise, clear and concise, not too much modification, mostly written language based, with high specification, suitable for cross-cultural business environment. It contains a large number of business theory and information, and business professionals are closely related, highly professional. Official statements fairly standard, with some structural complexity can be applied to any form of written contracts and other documents without abrupt feeling. A good business English translation of materials should focus its statement arranged logically structured, accurately grasp the long sentences and phrases proportional relationship, can not appear too many long sentences, so that relatively lengthy article, read not smooth; can not be used more phrase, the article is divided into a number of small parts, not the whole feeling, people read very trivial, the impact of the translation of the official materials. Only appropriate benefits to using the phrase yield long sentences in order to effectively improve business English translation.

Business English in describing the product information, must have a specific name and number of clear, not ambiguous, to the recipient of a general feeling that the impact their impression of the company.

However, because of cultural differences hinder, after translation is completed although the basic meaning of translation material is correct, but has lost its cultural imagery, so well-known trademarks original story people do not understand the specific meaning translated. For example, in the process of China's cultural heritage, has been rich yellow color as the emperor, "The Apprentice," said the ancient, some companies use yellow as a cultural tone of corporate trademark whichever is auspicious meaning, a symbol of the company's future bright prospects; however Westerners, yellow symbolizes the betrayal and vulgar, in business activities if some unknown to the Western companies see China company trademark literal content containing yellow wordings, it will produce the company's poor impression, lead directly to business communication activities 
unnecessary communication difficulties, which is in the business during the Cultural Images in English Translation missing specific performance.

For example: The goods of your order have been shipped.

It ordered the goods have been delivered consignments.

This translation obviously too abstract, there is no detailed description of the goods, quantity, give the counterparty a very casual feel, affect the follow-up business activities.

In view of this situation, we can make changes:

Your order for 5000 camera equipment has been shipped.

Your company ordered 5,000 sets of photographic equipment has been delivered consignment.

As a result, it becomes much more formal, the other showing enough respect, bilateral relations have maintained a good deal and can continue to trade exchanges. Another point to note is that the deal is in the business activities of the two sides should show enough courtesy, which should also be in business English translation of the full reflected. Specific measures are: Note the use of honorifics when translation of materials to minimize the more straightforward language exchange; to maintain the attitude of humility and sincere, words euphemism, but not beat about the bush, timely delivery of useful information; set themselves for the sake of each other, to remain calm when conflict dispute , courteous one-third do decide; exalting, written in English should be multipurpose Great, Excellent, etc. commendatory, the other side is willing to feel comfortable with the heart first business communication activities; by helping to timely thanks, and expressed his sincerity.

\section{REFLECT BUSINESS ENGLISH TRANSLATION IN CULTURAL DIFFERENCES}

Western geographical and cultural customs have great differences, these differences directly reflected in the language. Because of cultural differences, different people may be treated the same thing have very different views and ideas, which is no longer anything in common English translation process, as long as the teacher in a timely manner to make the students understand correct errors would not have generated translation too much influence; but in the business English translation will be buried deep problems, it may make translators committed a fatal error when doing business translation work, a direct result of business communication activities can not be carried out smoothly, the company with to a greater loss. Only when the Business English learning into the Western culture, so translators proficient in English translation skills but also on Chinese and Western cultures have a comprehensive understanding in order to make them handy in the actual translation work, to avoid the problem of cultural differences error appears. To deal with cultural differences to be perfect, we must first of cultural differences in business English translation of embodied have a general understanding.

Some of our professional business English translators at foreign trademark or content in English translation, translation methods commonly used to combine literal translation and, for some Western meaning quite different materials on the introduction of paraphrase translation methods. However, because of cultural differences hinder, after translation is completed although the basic meaning of translation material is correct, but has lost its cultural imagery, so well-known trademarks original story people do not understand the specific meaning translated. For example, in the process of China's cultural heritage, has been rich yellow color as the emperor, "The Apprentice," said the ancient, some companies use yellow as a cultural tone of corporate trademark whichever is auspicious meaning, a symbol of the company's future bright prospects; however Westerners, yellow symbolizes the betrayal and vulgar, in business activities if some unknown to the Western companies see China company trademark literal content containing yellow wordings, it will produce the company's poor impression, lead directly to business communication activities unnecessary communication difficulties, which is in the business during the Cultural Images in English Translation missing specific performance.

Western cultural differences largely affected the nation in the Western concept of different perspectives, even in the view of the same thing will be very different, even opposite. So we business English translators should be fully based on cultural differences, try to translate the original appearance of the material, but also the viewer the impression of a more accurate and objective; if certain material compared to literal translation than the original meaning large deviations occur, we should combine use paraphrase approach, meaning its internal reservation 
translation, eliminate misunderstandings caused due to cultural differences. The translation process, the translator should take into account the culture and customs of the basic connotation and translation of materials for the audience, theory with practice, so that the results fit the local culture translation language habits maximum extent to ensure objectivity and cultural business English translation Results sex.

\section{BUSINESS ENGLISH TRANSLATION CROSS CULTURAL CONTEXT}

Business English translation is not a simple English to Chinese or Chinese to English in the process, in addition to taking into account the syntax is correct, reasonable structure, meaning the standard, we should also pay attention to cultural differences, will translate the content as much as possible with their own cultural fusion translation of one of the most practical combination of culture, can do for the public to accept work. In the English translation process is to follow "Faithfulness" principle, especially in the translation of business English material. Translation of the three principles of the "letter" principle, referring to the translation of words must be accurate; we can not have altered the basic meaning or omission, to totally faithful reproduction of the original translation. This is the basis and prerequisite for business English translation activities, only accurate translation in place to ensure the smooth conversion of different cultures, to lay a good language base for business activities Foundation. For example, in translating business contract, each of them must be carefully translate an English word can not have passed over or lied phenomenon, "offer" can only be translated as "offer", "offeree" is the "offeree "can not change correctly understand the meaning of the word affect business objects.

Translation of the three principles in the "up" principle, referring to the translation to be in full compliance with the original, every word can be found in each one corresponding portion in the original, not just changes in changes, they can not join the translator own emotional and personal views. Implementation of this principle requires the translator has some experience and knowledge of business English translation, translation of materials was able to complete a business place, do not stay dead. Business English translation not only requires the original and the translation correspondence, but also to ensure proper convergence between words, the statement fluent, the viewer glance, fully understand the original author of the original meaning of the business material, laying a good for the entire business activities basis.

Translation of three principles "Elegance" principle refers to both the translation after translation concise, comprehensive and dignified nature, subject to a business fluent and beautiful first impression, both read catchy, concise brief, not dragging its feet, cumbersome, lengthy, as well as a sense of solemnity business written. This is the highest standard of business English translators, but also a high level of translation necessary prerequisite. Translators only continue to strengthen their own learning, and cultural aspects of the case have been covered knowledge, in order to better implement this principle effectively promote cross-cultural context of business English translation level. It contains a large number of business theory and information, and business professionals are closely related, highly professional. Official statements fairly standard, with some structural complexity can be applied to any form of written contracts and other documents without abrupt feeling. A good business English translation of materials should focus its statement arranged logically structured, accurately grasp the long sentences and phrases proportional relationship, can not appear too many long sentences, so that relatively lengthy article, read not smooth; can not be used more phrase, the article is divided into a number of small parts, not the whole feeling, people read very trivial, the impact of the translation of the official materials. Only appropriate benefits to using the phrase yield long sentences in order to effectively improve business English translation.

\section{CONCLUSION}

All in all, the actual work of the Intercultural Communication in Business English Translation of having considerable difficulty, to take into account the English translation of basic skills and language features, but also for various cultural differences have to understand, which requires us professional translators should continue to strengthen their own learning, so many ways to protect their own English translation standards improve, provide better support for the business activities of enterprises. 


\section{REFERENCES}

Ren Yi, Liu Xiaohai, Liao listen based on C/S and B/S hybrid architecture with examples of analysis Computer Engineering and Applications 2001 (16): 159-160

Pengyue Ping Design Laboratory Information Management System CS and BS binding mode of the microprocessor-based electrical and computer science, 2006,23 (8): 187-189

$\mathrm{Xu}$ Scots, had feathers, a Pender Software Engineering Theory and Practice of Beijing: Higher Education Press, 2004: 24

Zhao Qing double, smell Spark, Liang Guohua Development and Application of Experimental Technology and Management Laboratory Information Management Systems, 2000, 17 (6): 3032

Pengrui Dong, Maoling Tao, Ju Young Design and implementation of database management laboratory experimental techniques and management 200421 (2): 172-177

Tang Chenghua, Chen degrees, Chen new management information system research and multi-user rights management Computer Application Research, 2004, (3): 217-219

Liu onions, Chen Zhigang, Wu decided WEB-based management information of college open laboratory system Computer and Information Technology, 2000,5: 25-28

Zhou Ning, Wu open integration technology and ultra .WEB database Beijing: Tsinghua University Press, 2005 